\title{
Associations between pregnancy-associated glycoproteins and pregnancy outcomes, milk yield, parity, and clinical diseases in high-producing dairy cows
}

\author{
P. M. Mercadante, ${ }^{*}$ E. S. Ribeiro, $†$ C. Risco, $\ddagger$ and A. D. Ealy $\S^{1}$ \\ *Department of Animal Sciences, University of Florida, Gainesville 32611 \\ †Department of Animal Biosciences, University of Guelph, Guelph, ON N1G 2W1 Canada \\ ‡Department of Large Animal Clinical Sciences, University of Florida, Gainesville 32611 \\ $\S$ Department of Animal and Poultry Sciences, Virginia Tech, Blacksburg 24061
}

\section{ABSTRACT}

Pregnancy-associated glycoproteins (PAG) are produced by the ruminant placenta and secreted into the maternal circulation throughout pregnancy. The extent to which circulating PAG concentrations predict pregnancy outcomes was examined herein. Also, associations between circulating PAG concentrations and various production parameters and clinical diseases were evaluated. Lactating primiparous and multiparous Holstein cows $(\mathrm{n}=345)$ were bred via timed artificial insemination using a standard Ovsynch protocol. Pregnancy was diagnosed by transrectal ultrasonography at d 32, 46, and 74 of gestation. Blood was harvested at d 32 to determine plasma concentrations of PAG and progesterone. Cows pregnant at d 32 that subsequently lost their pregnancy at d 46 and 74 had reduced PAG concentrations. Both artificial insemination service number and parity were associated with plasma PAG concentrations. Concentration of PAG in plasma was greater for cows pregnant from their second or later breeding than those pregnant from the first breeding postpartum, and was increased for primiparous compared with multiparous. In addition, cows with greater milk yield had increased plasma PAG concentrations. No association was detected between body condition score and plasma PAG concentrations. Cows that experienced clinical metritis, metabolic problems, or left displacement abomasum in the early postpartum period preceding breeding had greater plasma PAG concentrations than cows not experiencing these clinical diseases. Also, cows with multiple clinical diseases had increased odds of pregnancy loss when compared

Received November 4, 2015.

Accepted December 20, 2015.

${ }^{1}$ Corresponding author: ealy@vt.edu with cows not experiencing clinical diseases. Odds ratio testing detected a tendency in the relationship between reduced milk yield and increased pregnancy loss. Collectively, these associations illustrate one feature of the early developing placenta that may predict pregnancy outcomes in dairy cattle. It is unclear if plasma PAG are actively involved with mediating pregnancy outcomes, but modifications in circulating PAG concentrations due to pregnancy loss, milk yield, parity, and clinical disease implicate placental PAG production or PAG release as being responsive to various physiological stimuli.

Key words: placenta, pregnancy loss, clinical disease, milk yield

\section{INTRODUCTION}

Pregnancy-associated glycoproteins (PAG) are aspartic proteases released in the maternal bloodstream from binucleate cells (BNC; also known as trophoblast giant cells) of the ruminant placenta throughout most of pregnancy (Sasser et al., 1986; Green et al., 1998; Telugu et al., 2009). The PAG are implicated for playing roles in placental-endometrial adhesion and fetal antigen sequestering (Wooding et al., 2005), but they are best known for their use in pregnancy diagnosis in cattle and other ruminants (Sasser et al., 1986; Green et al., 2005). Moreover, reductions in circulating PAG concentrations during early pregnancy also are associated with pregnancy failures in dairy and beef cattle (Thompson et al., 2010; Pohler et al., 2013; Ribeiro et al., 2014).

Lactation-induced infertility is one of the greatest costs associated with the US dairy cow industry (Bellows et al., 2002). Pregnancy losses are rampant in lactating dairy cows, ranging from 20 to $50 \%$ of all fertile matings (Santos et al., 2004). Infertility is a multifaceted problem. High-producing dairy cows contain reduced circulating steroid hormone concentrations 
(Santos et al., 2004), are more susceptible to heat stress (Wilson et al., 1998), poorly exhibit estrus expression (Lucy, 2001; Sartori et al., 2002), and have reduced oocyte competency and embryo quality (Sartori et al., 2002).

Cow health and successful metabolic transition from a nonlactating to lactating state at parturition are also key components of fertility. Cows that make this transition without adverse clinical disorders (e.g., retained placentae, metritis, severe negative energy balance, metabolic diseases) usually are among the highest producing cows in the herd, and these high-producing cows usually are more fertile than moderate and low producers, which exhibit at least one clinical disorder in the early postpartum period at a higher likelihood than the high-producing cows (Lucy, 2001; Vasconcelos et al., 2011).

The objectives of this study were to (1) determine the association between plasma PAG concentrations collected at d 32 of pregnancy with subsequent pregnancy loss in lactating dairy cattle, (2) determine associations between plasma PAG concentrations with production variables and peri- and postpartum diseases, and (3) define associations between peri- and postpartum diseases with pregnancy loss.

\section{MATERIALS AND METHODS}

All animal experimentation was completed in accordance with and with the approval of the Institute of Food and Agricultural Sciences Animal Care and Use Committee at the University of Florida.

\section{Experimental Design}

The study was conducted at the University of Florida Dairy Research Unit (Alachua) during 2 time periods: (1) August 2010 to February 2011, and (2) October 2011 to January 2012. Lactating primiparous and multiparous cows were maintained on a diet to equal or exceed protein and energy requirements for maintenance and milk production in accordance with the NRC (2001). The diet was based on alfalfa hay, corn silage, whole cottonseed, soybean hulls, corn grain, citrus pulp, soybean meal, and a mineral-vitamin premix, and designed to contain approximately $16.8 \% \mathrm{CP}$, $5.2 \%$ ether extract, $1.7 \% \mathrm{NE}_{\mathrm{L}}$, and $35.9 \% \mathrm{NDF}$. Cows did not receive glucogenic or calcium supplementation postpartum. Cows were milked twice daily throughout lactation.

A Presynch-Ovsynch-56 protocol was used to synchronize the first postpartum timed AI (Pursley et al., 1997). Presynch was conducted by administering
$\mathrm{PGF}_{2 \alpha}$ (25 mg; Lutalyse, Zoetis Inc., Madison, NJ) twice at a 14-d interval. At $11 \mathrm{~d}$ after the second $\mathrm{PFG}_{2 \mathrm{\alpha}}$ injection, GnRH was provided (100 $\mu$ g; Factrel, Zoetis Inc.) followed $7 \mathrm{~d}$ later by $\mathrm{PGF}_{2 \alpha}$ and $56 \mathrm{~h}$ thereafter by a second $\mathrm{GnRH}$ injection. Between 16 to $20 \mathrm{~h}$ later, AI was performed (average $=82 \mathrm{~d}$ postpartum). A total of 18 sires were used over the course of the study. Transrectal ultrasonography was completed to diagnose pregnancy at d 32 post-AI by using a portable US scanner (Easi-Scan, BCF Technology, Livingston, UK). The Ovsynch-56 protocol and timed AI was completed in second and subsequent services for cows diagnosed as nonpregnant at d 32 post-AI. In most cases, the semen from the same bull was used for repeated breedings of the same cow.

Blood was collected by coccygeal venipuncture immediately after pregnancy diagnosis (d 32 post-AI; EDTA-coated Vacutainer; Becton Dickinson, Franklin Lakes, NJ). Only pregnant cows on d 32 after AI $(\mathrm{n}=345)$ were enrolled in the experiment. Samples were placed in ice, transported to the laboratory, and centrifuged for plasma separation $(1,500 \times g, 15 \mathrm{~min}$, $\left.4^{\circ} \mathrm{C}\right)$. Plasma was frozen at $-20^{\circ} \mathrm{C}$ until analysis of progesterone (P4) and PAG. Pregnancy retention was examined at d 46 and 74 post-AI by using transrectal ultrasonography. Pregnancy maintenance to term was determined by monitoring calving. Cows that lost their pregnancy were not used again if they were confirmed pregnant on a subsequent cycle.

\section{Progesterone and PAG Analyses}

Plasma P4 concentrations were determined by a solid-phase RIA (Coat-A-Count Progesterone kit, DPC Diagnostic Products Corp., Los Angeles, CA; Seals et al., 1998). The standard curve dilution consisted of duplicate uncoated tubes for total counts and nonspecific binding, and a $100-\mu \mathrm{L}$ aliquot of increasing progesterone concentrations $(0.1,0.25,0.5,1,2,5,10$, and 20 $\mathrm{ng} / \mathrm{mL}$ ). Control samples were included multiple times on each assay. The intra-assay coefficients of variation were 1.8 and $3.7 \%$ for samples analyzed in the first and second period of the study, respectively. The same control samples were analyzed in both periods.

Circulating plasma PAG concentrations were determined by ELISA as described previously (Green et al., 2005) with slight modifications in Jonathan Green's laboratory at the University of Missouri, Columbia. A pool of 3 anti-PAG monoclonal antibodies recognizing different binucleate cell-specific PAG (bPAG4, 6, 7, 16, 20 , and 21) was used as trapping antibodies. A polyclonal antiserum with broad specificity for PAG was used as the primary antibody, and an alkaline phos- 
phatase-conjugated anti-rabbit antibody served as the detector. Serial dilutions of PAG standards (prepared in nonpregnant heifer serum) were added to duplicate wells for the standard curve. All samples and standards were completed in duplicate. Intra- and interassay coefficients of variation were 11.4 and $11.1 \%$, respectively, for the first year of the study and 7.2 and $6.4 \%$, respectively, in the second year.

\section{Characterization of Health Problems}

All data were collected by Dairy Research Unit staff and the University of Florida Food Animal Veterinary staff and students and recorded onto the AfiFarm Net 3.07 system (Afimilk, Kibbutz Afikim, Israel). Data were examined beginning at the calving preceding the pregnancy under investigation and continued until the following calving event. Calving problems included dystocia (i.e., requiring assisted calving), twin calving, and fetal membranes retained for $>24 \mathrm{~h}$. Metabolic problems included ketosis (violet color in the Ketostix Reagent Strips), and hypocalcemia [cow laying down or unsteady before calving to $2 \mathrm{~d}$ after calving; treated with 500 to $750 \mathrm{~mL}$ of calcium borogluconate $(23 \%$, wt/vol, solution), i.v.]. Clinical diseases included metritis (brownish fetid vaginal discharge on the first 10 d postpartum), clinical mastitis (presence of abnormal milk examined at each milking), lameness (foot rot, digital dermatitis, laminitis, subsolar abscess), digestive problems (bloat, diarrhea), left displaced abomasum (LDA), and respiratory problems (cough, increased lung sounds at auscultation).

\section{Additional Information Collected}

Additional parameters examined included sire, insemination number ( 1 vs. $\geq 2$ ), and parity (primiparous vs. multiparous). Milk yield adjusted for 305-d (M305Q) was grouped in quartiles $(\mathbf{Q} 1=8,577 \pm$ $122 \mathrm{~kg} ; \mathbf{Q} 2=10,822.1 \pm 154.2 \mathrm{~kg} ; \mathbf{Q 3}=11,974.2 \pm$ $170.8 \mathrm{~kg} ; \mathbf{Q} 4=13,641.1 \pm 194 \mathrm{~kg}$ ). Body condition scores were completed at d 32 of pregnancy using a 5 -point scoring system (Ferguson et al., 1994). Cows were grouped into high $(\geq 3.75)$, moderate (3 to 3.5 ), and low $(\leq 2.75)$ categories. Also, gestation length, calf sex, and calving problems were examined.

\section{Statistical Analysis}

All data were analyzed by the SAS statistical software version 9.3 (SAS/STAT; SAS Institute Inc., Cary, NC). Continuous data were analyzed by ANOVA fitting a Gaussian data distribution, and binary responses were analyzed by logistic regression fitting a binary data distribution using the GLIMMIX procedure of SAS. Simple correlation analysis between PAG and progesterone was performed using the CORR procedure of SAS.

To identify factors associated with concentrations of PAG in plasma, a multivariable model including the effects of parity, categorized service number $(1$ or $\geq 2)$, categorized M305Q (quartiles), period of the study (1 or 2), categorized BCS (low, moderate, and high), and AI sire was used initially to explain the observed variability in PAG concentrations. Explanatory variables that resulted in $P<0.05$ were considered associated with concentrations of PAG in plasma and used as covariates to investigate the association between PAG and diseases, and between PAG and pregnancy loss.

To identify factors associated with pregnancy loss, a multivariable model including the effects of parity, categorized service number ( 1 or $\geq 2)$, categorized M305Q (quartiles), period of the study (1 or 2), categorized BCS (low, moderate, and high), and AI sire was used initially to explain the observed variability in pregnancy loss. Explanatory variables that resulted in $P$ $<0.05$ were considered associated with pregnancy loss and used as covariates to investigate the association between categorized PAG (quartiles) and pregnancy loss, and between diseases and pregnancy loss.

\section{RESULTS}

\section{Circulating PAG Concentrations and Pregnancy Loss}

A pregnancy loss of $16.1 \%$ was observed during the experimental period (Table 1). Pregnancy losses occurred at a similar rate between d 32 and 46 , between d 46 and 74 , and after d 74. A reduction $(P=0.002)$ in pregnancy loss was detected in cows pregnant from their first insemination versus those pregnant from their second or greater insemination (13 versus $18 \%$, respectively, $\mathrm{SE}=0.08)$. Sire and parity did not affect pregnancy loss (data not shown).

Associations between circulating PAG concentrations at d 32 and pregnancy loss after d 32 of pregnancy were examined in 2 ways. The first examined PAG concentrations at $d 32$ of gestation between cows that experienced pregnancy loss after $d 32$ versus those that maintained pregnancies to term (Table 1). Circulating PAG concentrations were reduced $(P<0.05)$ in cows experiencing pregnancy loss after d 32 when compared with cattle that maintained their pregnancy to term. Reductions in circulating PAG concentrations were evident when cattle were categorized based on the time 
Table 1. Association between pregnancy loss and concentrations of pregnancy-associated glycoproteins (PAG) or progesterone (P4) in plasma of pregnant cows on $\mathrm{d} 32$ of gestation ${ }^{1}$

\begin{tabular}{|c|c|c|c|c|c|c|c|}
\hline \multirow[b]{2}{*}{ Item } & \multirow{2}{*}{$\begin{array}{c}\text { Preg. loss } \\
(\%)\end{array}$} & \multicolumn{3}{|c|}{$\mathrm{PAG},{ }^{3} \mathrm{ng} / \mathrm{mL}$} & \multicolumn{3}{|c|}{$\mathrm{P} 4, \mathrm{ng} / \mathrm{mL}$} \\
\hline & & No (n) & Yes (n) & $P$-value & No $(n)$ & Yes (n) & $P$-value \\
\hline Preg. loss: d 32-46 & 4.3 & $8.34 \pm 0.24(330)$ & $6.50 \pm 0.89(15)$ & 0.008 & $7.29 \pm 0.20(330)$ & $5.90 \pm 0.89$ & 0.17 \\
\hline Preg. loss: d $46-74$ & 5.8 & $8.39 \pm 0.25$ & $6.96 \pm 0.90$ & 0.30 & $7.29 \pm 0.20$ & $7.32 \pm 0.81(19)$ & 0.66 \\
\hline Preg. loss: d 32-74 & 9.8 & $8.39 \pm 0.25(310)$ & $6.76 \pm 0.67(34)$ & 0.01 & $7.29 \pm 0.20(276)$ & $6.69 \pm 0.61(34)$ & 0.55 \\
\hline Preg. loss after d 74 & 6.4 & $8.46 \pm 0.26(276)$ & $7.43 \pm 0.81(19)$ & 0.13 & $7.38 \pm 0.21(276)$ & $7.26 \pm 0.78$ & 0.79 \\
\hline
\end{tabular}

${ }^{1}$ Results shown as mean \pm SE.

${ }^{2}$ Preg. loss = pregnancy loss after pregnancy diagnosis at d 32 post-AI.

${ }^{3} \mathrm{PAG}, \mathrm{ng} / \mathrm{mL}=$ plasma concentration of pregnancy-associated glycoprotein.

when pregnancy loss occurred (Table 1). Cattle that experienced pregnancy loss between d 32 and 46 and between d 32 and 74 contained reduced $(P<0.05)$ circulating PAG concentrations at d 32 . However, cattle that underwent pregnancy loss between $\mathrm{d} 46$ and 74 or after d 74 did not experience changes in circulating PAG concentrations at $\mathrm{d} 32$.

The second analysis used odds ratio analysis to examine associations between circulating PAG concentrations at d 32 and subsequent pregnancy loss (Table 2). Cattle were sorted into quartiles based on their plasma PAG concentrations at $d 32$. Cows with the lowest circulating PAG concentrations (Q1) experienced a 2.85-fold increase in their probability of experiencing pregnancy loss versus cows with the greatest circulating PAG concentrations (Q4; $P=0.02$ ). Also, tendencies for increased probabilities for pregnancy loss were detected between d 32 and 74 and after d 74 for cows containing the lowest and greatest circulating PAG concentrations at $\mathrm{d} 32(P=0.09$ and 0.1 , respectively). No differences in probabilities of pregnancy loss between d 32 and 46 or d 46 to 74 were detected based on circulating PAG concentrations at d 32 (data not shown).

No changes in circulating P4 concentrations at d 32 of gestation were detected between cattle that subse- quently underwent pregnancy loss versus those that maintained their pregnancy (Table 1). Also, no correlation was found between circulating PAG concentrations and circulating $\mathrm{P} 4$ concentrations at $\mathrm{d} 32$ of gestation $(\mathrm{r}=0.2 ; P=0.23$; data not shown $)$.

\section{Circulating PAG Concentrations and Parity, Insemination Number, BCS, and Milk Yield}

Circulating PAG concentrations at d 32 was correlated with several animal traits (Table 3). Primiparous cows contained greater PAG concentrations than multiparous cows $(P=0.002)$. Also, regardless of parity, cows pregnant on their first service had reduced circulating PAG concentrations at $\mathrm{d} 32$ than cows pregnant on or after their second service $(P=0.002)$. Body condition score at d 32 was not associated with PAG concentrations. Plasma PAG concentrations were associated with milk yield $(P=0.03)$. Plasma PAG concentrations were greater in cattle within the high milk yield quartiles (Q3 and Q4) than cattle in the lowest producing quartile (Q1; $P<0.05)$. Also, cattle in Q3 contained greater PAG concentrations than cows in Q1, Q2, or Q4 $(P<0.05)$. Circulating PAG concentrations were not affected by sire $(P=0.19)$.

Table 2. Probabilities of pregnancy loss based on circulating pregnancy-associated glycoproteins (PAG) concentrations at d 32 of gestation

\begin{tabular}{|c|c|c|c|c|c|c|}
\hline \multirow[b]{2}{*}{ PAG quartile ${ }^{1}$} & \multicolumn{2}{|c|}{$\begin{array}{l}\text { Pregnancy loss } \\
\quad(\mathrm{n}=53)\end{array}$} & \multicolumn{2}{|c|}{$\begin{array}{l}\text { Pregnancy loss d } 32-74 \\
\quad(\mathrm{n}=34)\end{array}$} & \multicolumn{2}{|c|}{$\begin{array}{l}\text { Pregnancy loss after d } 74 \\
(\mathrm{n}=19)\end{array}$} \\
\hline & $\begin{array}{c}\mathrm{AOR}^{2} \\
(95 \% \mathrm{CI})\end{array}$ & $P$-value & $\begin{array}{c}\mathrm{AOR} \\
(95 \% \mathrm{CI})\end{array}$ & $P$-value & $\begin{array}{c}\mathrm{AOR} \\
(95 \% \mathrm{CI})\end{array}$ & $P$-value \\
\hline$\overline{\mathrm{Q} 4}$ & 1.00 & - & 1.00 & - & 1.00 & - \\
\hline Q3 & $1.13(0.44-2.90)$ & 0.80 & $1.11(0.35-3.57)$ & 0.86 & $1.04(0.24-4.45)$ & 1.00 \\
\hline Q2 & $0.93(0.35-2.48)$ & 0.88 & $0.96(0.29-3.22)$ & 0.95 & $0.83(0.17-4.02)$ & 0.82 \\
\hline
\end{tabular}

${ }^{1}$ The concentration of plasma pregnancy-associated glycoprotein (PAG) categorized in quartiles (Q), with Q4 containing cows with the greatest and Q1 the least plasma PAG concentrations.

${ }^{2} \mathrm{AOR}=$ adjusted odds ratio. 
Table 3. Effect of various traits on circulating pregnancy-associated glycoproteins (PAG) concentrations in plasma of pregnant dairy cows on d 32 after AI $(\mathrm{n}=345)$

\begin{tabular}{lrcc}
\hline Trait & $\mathrm{N}$ & $\begin{array}{c}\mathrm{PAG}^{1} \\
(\mathrm{ng} / \mathrm{mL})\end{array}$ & $P$-value \\
\hline Parity & & & \\
$\quad$ Primiparous & 129 & $9.06 \pm 0.42$ & 0.002 \\
$\quad$ Multiparous & 216 & $7.79 \pm 0.31$ & \\
1st service & 174 & $7.73 \pm 0.34$ & 0.002 \\
Z2nd service & 171 & $8.77 \pm 0.34$ & \\
BCS & & & \\
High & 52 & $7.85 \pm 0.63$ & 0.39 \\
Moderate & 259 & $8.32 \pm 0.28$ & \\
Low & 34 & $8.42 \pm 0.77$ & \\
M305Q & & & \\
Q4 & 85 & $8.18 \pm 0.49^{\mathrm{a}}$ & 0.03 \\
Q3 & 86 & $9.66 \pm 0.49^{\mathrm{b}}$ & \\
Q2 & 86 & $8.06 \pm 0.49^{\mathrm{ac}}$ & \\
Q1 & 85 & $7.25 \pm 0.49^{\mathrm{c}}$ & \\
\hline
\end{tabular}

${ }^{\mathrm{a}-\mathrm{c}}$ Different superscripts indicate differences between individual quartiles for M305Q $(P<0.05)$.

${ }^{1}$ Results shown as least squares means $\pm \mathrm{SE}$.

${ }^{2}$ Average scores $=\operatorname{high}(3.79 \pm 0.05)$, moderate $(3.27 \pm 0.02)$, low $(2.64 \pm 0.06)$.

${ }^{3} \mathrm{M} 305 \mathrm{Q}$ is the milk yield adjusted for $305 \mathrm{~d}$ categorized in quartiles (Q), with Q4 having the greatest and Q1 the least milk production. Average yields: Q4 $(13,641.1 \pm 242.8 \mathrm{~kg})$, Q3 $(11,974.2 \pm 240.6 \mathrm{~kg})$, Q2 $(10,822.1 \pm 237.9 \mathrm{~kg})$, Q1 $(8,577 \pm 241.8 \mathrm{~kg})$.

\section{Circulating PAG Concentrations and Clinical Diseases}

Circulating PAG concentrations at d 32 of gestation were not associated with clinical diseases occurring before breeding (Table 4). The presence of either a single or multiple clinical disorders of any category did not affect PAG concentrations. However, cattle that experienced metritis, metabolic problems (e.g., ketosis, milk fever), or LDA had greater circulating PAG concentrations than cows not experiencing these diseases $(P=$ $0.01)$. This effect was only evident when the conditions were examined together (termed MML: metritis, metabolic problems, and LDA combined). None of these parameters were associated with PAG concentrations when data were categorized based on service number (data not shown).

Associations between circulating PAG concentrations and clinical disorders that occurred after d 32 of gestation also were examined (Table 4). No associations were evident between PAG concentrations and individual disorders that occurred during pregnancy with the exception of a tendency for cows experiencing dystocia at

Table 4. Effect of clinical diseases on circulating pregnancy-associated glycoproteins (PAG) concentrations in plasma if pregnant dairy cows on d 32 of gestation $(\mathrm{n}=345)^{1}$

\begin{tabular}{|c|c|c|c|c|}
\hline \multirow[b]{2}{*}{ Health problem } & \multicolumn{4}{|c|}{$\mathrm{PAG}, \mathrm{ng} / \mathrm{mL}$} \\
\hline & $\mathrm{N}^{2}$ & No & Yes & $P$-value \\
\hline Single clinical disease ${ }^{3}$ & 110 & $7.64 \pm 0.45$ & $8.50 \pm 0.29$ & 0.31 \\
\hline Multiple clinical diseases & 136 & - & $8.85 \pm 0.38$ & 0.17 \\
\hline \multicolumn{5}{|c|}{ Diseases occurring before d 32 of pregnancy ${ }^{4}$} \\
\hline Metritis & 96 & $7.84 \pm 0.29$ & $9.34 \pm 0.46$ & 0.19 \\
\hline Metabolic problems & 93 & $8.15 \pm 0.28$ & $8.53 \pm 0.47$ & 0.45 \\
\hline Ketosis & 89 & $8.16 \pm 0.28$ & $8.54 \pm 0.48$ & 0.48 \\
\hline Hypocalcemia & 10 & $8.26 \pm 0.25$ & $9.25 \pm 1.43$ & 0.39 \\
\hline LDA & 16 & $8.12 \pm 0.25$ & $11.03 \pm 1.13$ & 0.17 \\
\hline $\mathrm{MML}^{5}$ & 156 & $7.67 \pm 0.33$ & $8.97 \pm 0.36$ & 0.01 \\
\hline Dystocia $^{6}$ & 39 & $8.17 \pm 0.26$ & $8.90 \pm 0.72$ & 0.70 \\
\hline Mastitis & 123 & $8.17 \pm 0.30$ & $8.40 \pm 0.41$ & 0.51 \\
\hline Respiratory & 19 & $8.25 \pm 0.25$ & $8.31 \pm 1.04$ & 0.75 \\
\hline Digestive & 40 & $8.16 \pm 0.26$ & $9.01 \pm 0.72$ & 0.25 \\
\hline Lameness & 43 & $8.28 \pm 0.26$ & $8.07 \pm 0.69$ & 0.66 \\
\hline \multicolumn{5}{|c|}{ Diseases occurring after d 32 of pregnancy ${ }^{7}$} \\
\hline Mastitis & 94 & $8.04 \pm 0.29$ & $8.85 \pm 0.46$ & 0.87 \\
\hline Digestive & 12 & $8.25 \pm 0.25$ & $8.48 \pm 1.32$ & 1.00 \\
\hline Lameness & 87 & $8.32 \pm 0.28$ & $8.08 \pm 0.48$ & 0.61 \\
\hline Calving problems & 27 & $8.52 \pm 0.29$ & $7.92 \pm 0.87$ & 0.08 \\
\hline \multicolumn{5}{|c|}{${ }^{1}$ Results shown as mean $\pm \mathrm{SE}$. } \\
\hline \multicolumn{5}{|c|}{${ }^{2}$ Number of cattle represented in each parameter. } \\
\hline \multicolumn{5}{|c|}{${ }^{3}(\mathrm{n})$ is the number of animals that presented with the specific disease. } \\
\hline \multicolumn{5}{|c|}{${ }^{4}$ Diseases detected between parturition and pregnancy check at d 32 of gestation. } \\
\hline \multicolumn{5}{|c|}{$\begin{array}{l}{ }^{5} \mathrm{MML}=\text { metritis, metabolic problems, and left displaced abomasum (LDA) combined. Diseases that occurrec } \\
\text { within } 2 \text { wk postpartum. }\end{array}$} \\
\hline \multicolumn{5}{|c|}{${ }_{-}^{6}$ Calving problems related to previous pregnancy. } \\
\hline \multicolumn{5}{|c|}{${ }^{7}$ Diseases detected after pregnancy detection at d 32 of gestation. } \\
\hline
\end{tabular}


Table 5. Probability of pregnancy loss based on parity, BCS, and milk yield ${ }^{1}$

\begin{tabular}{llcc}
\hline \multicolumn{1}{c}{ AOR } & & \\
Trait & \multicolumn{1}{c}{$(95 \% \mathrm{CI})$} & $P$-value & Number \\
\hline Parity & & & \\
$\quad$ Primiparous & 1.00 & - & 129 \\
Multiparous & $1.02(0.53-1.99)$ & 0.95 & 216 \\
BCS & & & \\
Moderate & 1.00 & - & 259 \\
High & $0.80(0.29-2.23)$ & 0.67 & 52 \\
Low & $1.50(0.60-3.78)$ & 0.39 & 34 \\
M305Q & & & \\
Q4 & 1.00 & - & 85 \\
Q3 & $0.97(0.40-2.35)$ & 0.94 & 86 \\
Q2 & $0.58(0.22-1.52)$ & 0.27 & 86 \\
Q1 & $2.19(1.00-4.94)$ & 0.06 & 85 \\
\hline
\end{tabular}

${ }^{1}$ Results shown as mean $\pm \mathrm{SE}$. AOR $=$ adjusted odds ratio.

${ }^{2}$ Milk yield adjusted for 305 d categorized in quartiles (Q), with Q4 containing cows with the greatest and Q1 containing the lowest adjusted milk yield.

term to have reduced circulating PAG concentrations at d 32 of gestation $(P=0.08)$.

When only the cows that were pregnant following the first service were examined, mastitis was associated with an increase in circulating PAG concentrations $(8.32 \pm 0.39$ vs. $10.31 \pm 0.73 \mathrm{ng} / \mathrm{mL}$ of PAG for the absence and presence of mastitis, respectively; $P=$ $0.05)$. No other clinical diseases were associated with PAG concentrations after partitioning data based on service number (data not shown).

\section{Pregnancy Loss and Parity, BCS, Milk Yield, and Clinical Diseases}

Probabilities of pregnancy loss after d 32 were not influenced by parity or BCS (Table 5). A tendency for low milk yield to increase the probability of pregnancy loss $(P=0.06$; Table 5$)$ was observed. No changes in probabilities for pregnancy loss were detected when cattle were categorized based on service number (data not shown).

Multivariable logistic regression was used to evaluate the effect of clinical diseases before pregnancy on the probability of pregnancy loss after d 32. Animals were classified as having no disease, a single disease event, or 2 or more diseases before or during the pregnancy under investigation. When data from all pregnant cows were examined (Table 6), a single disease event did not affect pregnancy loss. However, cattle experiencing 2 or more clinical diseases had a greater probability of pregnancy loss after d $32(P=0.05)$. Multiple clinical diseases before pregnancy did not affect pregnancy loss between $d 32$ and 74 but tended to increase the probability of pregnancy loss after d $74(P=0.07)$.

A separate analysis examined the probabilities of pregnancy loss after d 32 in cows that were pregnant after their first service. A single disease event did not affect pregnancy loss, but 2 or more clinical diseases had a greater probability of pregnancy loss after d 32 in cows pregnant after their first service $(P=0.01)$. Multiple clinical diseases increased the probability of pregnancy loss between $\mathrm{d} 32$ and $74(P=0.04)$ but not after d 74. No relationships existed between clinical disease and pregnancy loss in cows that were pregnant in their second or later services (data not shown).

\section{DISCUSSION}

This study was conceived to provide insights into how various reproductive, metabolic, and health-related issues contribute to embryonic and fetal pregnancy losses in lactating dairy cattle. The primary focus of this work was to evaluate how circulating PAG concentrations associate with pregnancy loss and various production and clinical disease parameters.

In ruminants, PAG are generated from a diverse gene family (Telugu et al., 2009). All postimplantation

Table 6. Probability of pregnancy loss after d 32 based on the occurrence of a single or multiple clinical diseases before or during pregnancy

\begin{tabular}{|c|c|c|c|c|c|c|}
\hline \multirow[b]{2}{*}{ Health problem } & \multicolumn{2}{|c|}{$\begin{array}{l}\text { Pregnancy loss } \\
\quad(\mathrm{n}=53)\end{array}$} & \multicolumn{2}{|c|}{$\begin{array}{l}\text { Pregnancy loss d } 32-74 \\
\qquad(\mathrm{n}=34)\end{array}$} & \multicolumn{2}{|c|}{$\begin{array}{l}\text { Pregnancy loss after d } 74 \\
\qquad(\mathrm{n}=19)\end{array}$} \\
\hline & $\begin{array}{l}\text { Adjusted odds ratio } \\
(95 \% \mathrm{CI})\end{array}$ & $P$-value & $\begin{array}{l}\text { Adjusted odds ratio } \\
\quad(95 \% \mathrm{CI})\end{array}$ & $P$-value & $\begin{array}{c}\text { Adjusted odds ratio } \\
(95 \% \mathrm{CI})\end{array}$ & $P$-value \\
\hline \multicolumn{7}{|l|}{ All services } \\
\hline No diseases & 1.00 & - & 1.00 & - & 1.00 & - \\
\hline Single clinical disease & $0.79(0.32-1.95)$ & 0.60 & $0.84(0.30-2.39)$ & 0.75 & $0.69(0.13-3.57)$ & 0.65 \\
\hline No diseases & 1.00 & - & 1.00 & - & 1.00 & - \\
\hline Single clinical disease & $1.23(0.32-4.70)$ & 0.76 & $1.87(0.37-9.38)$ & 0.44 & $0.53(0.04-6.33)$ & 0.61 \\
\hline Multiple clinical disease & $4.39(1.41-13.6)$ & 0.01 & $4.28(1.04-17.6)$ & 0.04 & $3.90(0.67-22.7)$ & 0.13 \\
\hline
\end{tabular}


trophoblast cells produce PAG, but BNC produce the subset of PAG present in circulation (Green et al., 2000; Telugu et al., 2009). These circulating glycoproteins serve as excellent predictors of pregnancy in cattle and other ruminants on or after $28 \mathrm{~d}$ of gestation (Humblot et al., 1988; Green et al., 2005, Gajewski et al., 2008). This work examined PAG concentrations at d 32 of gestation, coincident with the initial transrectal ultrasonography pregnancy diagnosis in the University of Florida herd. A $16 \%$ pregnancy loss was observed. This is in line with other observations, where late embryonic (losses occurring between d 25 and 42 of gestation) and fetal losses (losses occurring after d 42) normally range from 10 to $18 \%$ in lactating dairy cows, although losses as great as $45 \%$ have been reported (Humblot, 2001; Santos et al., 2004; Inskeep and Dailey, 2005; Gabor et al., 2007). Also, like other studies, most of these pregnancy losses occurred before d 74 of gestation.

In this study, cows in the lowest quartile of circulating PAG concentrations were 2.85 times more likely to experience pregnancy loss than the remainder of the cows. Others also have observed reductions in circulating PAG concentrations in cows that undergo pregnancy loss (Gabor et al., 2007; Thompson et al., 2010; Ribeiro et al., 2014). In one study, a 10-fold increase in the odds of pregnancy loss was observed in lactating cows containing low circulating PAG concentrations at d 39 (Lopez-Gatius et al., 2007b). It is important to note that weak associations between PAG concentrations at d 32 and pregnancy loss after d 74 were detected. This likely signifies that PAG production in early pregnancy is associated with early placental development, or lack thereof, but that early PAG production cannot provide a predictive assessment of pregnancy loss after d 74, likely because some of these fetal losses are associated with placental insufficiencies and fetal abnormalities that have not manifested by d 32 of gestation (Santos et al., 2004).

Evidence supports the contention that cows containing greater $\mathrm{P} 4$ concentrations before implantation are more likely to become pregnant (Mann and Lamming, 2001; Inskeep, 2004; Parr et al., 2012). Also, evidence shows that postimplantation pregnancy losses are associated, at least in some cases, with low circulating P4 concentrations. In a recent study, cows with lower than normal circulating $\mathrm{P} 4$ concentrations were more likely to experience late embryonic and early fetal losses than cows with greater than normal circulating $\mathrm{P} 4$ (Gabor et al., 2007). In that same study, $90 \%$ of the cows containing both low P4 and low PAG concentrations at d 30 to 36 postbreeding experienced pregnancy loss (Gabor et al., 2007). Some reports detected associations between circulating P4 and PAG concentrations in early pregnancy, whereas no such associations were detected in other studies (Ayad et al., 2007; Bech-Sabat et al., 2008; Karen et al., 2014). No reports exist that examined whether P4 directly mediates PAG production from BNC, and conflicting reports exist for whether PAG control P4 production in cultured bovine and ovine luteal cells (Del Vecchio et al., 1995a,b, 1996; Weems et al., 1998, 2007). In the present study, no cows experienced low P4 concentrations at d 32 (as determined by concentrations $<2 \mathrm{ng} / \mathrm{mL}$ ), and this prevented detection of any possible association between P4 and pregnancy loss as well as between P4 and PAG. Nonetheless, it is clear from other literature that examining both $\mathrm{P} 4$ and PAG concentrations in early pregnancy will improve predictions of impending pregnancy failure.

In other work, high circulating PAG concentrations were also predictive of pregnancy loss. In one study, the risk of pregnancy loss was 6.8 times greater in cattle containing high circulating PAG concentrations in early pregnancy than those with average PAG concentrations (Lopez-Gatius et al., 2007b). Elevated circulating PAG concentrations also is indicative of impending pregnancy failure in pregnancies established from somatic cell nuclear transfer-derived embryos (Heyman et al., 2002; Chavatte-Palmer et al., 2006). It is not clear what influence elevated circulating PAG has on pregnancy outcomes, but it is tempting to speculate that elevated circulating PAG concentrations may reflect attempts for failing placentae to overcome a placental insufficiency. If PAG do play active roles at the placental-endometrial interface or in binding fetal antigens, as proposed by others (Wooding et al., 2005; Telugu et al., 2009), then these activities may assist with the maintenance of marginal pregnancies. Alternatively, perhaps the elevations in circulating PAG reflect the destruction of the fetal-placental unit, which may expel placental products into the maternal circulation. However, additional insights into PAG actions are needed before any firm functional relationships can be made between PAG concentrations and pregnancy outcomes. No extreme elevations in PAG concentrations were associated with failed pregnancies in this study. However, cattle that experienced metabolic disorders before breeding (metritis, metabolic problems, LDA) contained greater PAG concentrations than cows not experiencing these disorders. Perhaps additional PAG production is necessary for these cattle to overcome the residual effects of these metabolic disorders.

Several other novel associations with circulating PAG concentrations were detected in this study. It was unexpected that circulating PAG concentrations were not greatest in cows containing the greatest milk 
production, but rather concentrations were greatest in cows within the second quartile of milk production. In previous work (Lopez-Gatius et al., 2007a), no association between PAG concentrations and milk production was detected at d 35 of gestation, although those data were not segregated into quartiles. That same study determined an inverse relationship between circulating PAG concentrations and milk production at d 49 and 63 of gestation. The reason for reductions in PAG concentrations in high-producing cows may reflect elevated PAG degradation within the liver or clearance by the kidney (Sangsritavong et al., 2002). Alternatively, PAG are detected in milk (Gajewski et al., 2008), and PAG may be transferred from the plasma to milk in greater amounts in high-producing cows. Lastly, perhaps highproducing cows use PAG in different ways than other cows, and these PAG are preferentially sequestered in the placental-endometrial interface to assist with placental activity. This linkage between milk production and circulating PAG concentrations may also explain, at least in part, why multiparous cows have reduced PAG concentrations when compared with primiparous cows and why cows that were pregnant at first service contained reduced PAG concentrations compared with cows pregnant at their second or greater services.

Blood sampling did not occur before breeding and between services; thus, a definitive absence in circulating PAG concentrations cannot be discounted. However, the PAG assay used herein was designed to target PAG in early pregnancy, which generally have shorter halflives than those found later in gestation (Green et al., 2005). Previous work determined that PAG were either undetectable or $<0.5 \mathrm{ng} / \mathrm{mL}$ at d 42 postpartum when using this assay (Green et al., 2005); thus, cows used in this study contained no measurable PAG by the time of their first service. Also, it is highly unlikely that PAG concentrations in cows pregnant at their second and greater services were influenced by PAG secreted from pregnancies that failed before pregnancy detection at $\mathrm{d}$ 32 postbreeding. Circulating PAG concentrations will range from 1 to $8 \mathrm{ng} / \mathrm{mL}$ between d 22 and 32 of pregnancy (Green et al., 2005), and sufficient PAG clearance would have occurred by the next pregnancy check (approximately $41 \mathrm{~d}$ when including the time needed for re-synchronization before breeding). Circulating PAG are 2 orders of magnitude greater at term than they are at d 32 of pregnancy (Sasser et al., 1986), and by d 42 postpartum, circulating PAG concentrations are either undetectable or $<0.5 \mathrm{ng} / \mathrm{mL}$ when using the PAG assay employed here.

A linkage was found between PAG concentrations and clinical disease. Cows that experienced metritis, metabolic problems, LDA, or a combination of these before d 32 of pregnancy had greater PAG concentrations than cows that did not experience any of these disorders. Also, first-service cows experiencing mastitis before pregnancy detection possessed greater circulating PAG concentrations than cows not experiencing mastitis. It is not clear if these linkages relate to a possible immune-modulatory action for PAG. Additional exploration of these potential associations is needed, as insufficient animal numbers prevented detection of individual clinical diseases that may relate to changes in PAG concentrations. One linkage that would be especially interesting to pursue further is the possible association between PAG concentrations at d 32 of pregnancy and subsequent calving difficulties at term. It is conceivable that early predictors of placental development may also predict at least a subset of calving difficulties. Perhaps, for example, early PAG concentrations may be correlated with calf weight at term. The exact mechanisms responsible for this possible linkage remain unclear.

The final component of the work examined risk factors for late embryonic and fetal pregnancy losses independent of PAG concentrations. Neither parity nor BCS affected pregnancy loss. However, cows within the lowest quartile of milk production at d 32 of pregnancy were 2 times more likely to experience pregnancy loss than cows in the highest quartile for milk production. Also, cows that experienced multiple clinical diseases were more likely to experience pregnancy loss than cows not experiencing any clinical diseases. These observations are in agreement with previous work indicating a clear linkage between peri- and postpartum cow health on subsequent fertility (Santos et al., 2010; Vasconcelos et al., 2011; Ribeiro et al., 2013).

\section{CONCLUSIONS}

Changes in PAG concentrations in early pregnancy were predictive of pregnancy failure in lactating cows. Circulating PAG concentrations also were associated with several other parameters linked with pregnancy failure in cattle, including parity, AI service number, milk production, and metabolic diseases. It is not clear if altered PAG concentrations are a causative factor in late embryonic and early fetal pregnancy losses or if these changes merely reflect placental or systemic alterations existing in cattle with a greater propensity for pregnancy loss. Nonetheless, these outcomes provide additional evidence of how circulating PAG concentrations may predict pregnancy outcomes and potentially overall placental health. 


\section{ACKNOWLEDGMENTS}

Work was funded by the Southeast Milk Inc. Checkoff Program.

\section{REFERENCES}

Ayad, A., N. M. Sousa, J. Sulon, J. L. Hornick, J. Watts, F. LopezGatius, M. Iguer-Ouada, and J. F. Beckers. 2007. Influence of progesterone concentrations on secretory functions of trophoblast and pituitary during the first trimester of pregnancy in dairy cattle. Theriogenology 67:1503-1511.

Bech-Sabat, G., F. Lopez-Gatius, J. L. Yaniz, I. Garcia-Ispierto, P. Santolaria, B. Serrano, J. Sulon, N. M. de Sousa, and J. F. Beckers. 2008. Factors affecting plasma progesterone in the early fetal period in high producing dairy cows. Theriogenology 69:426-432.

Bellows, D. S., S. L. Ott, and R. A. Bellows. 2002. Cost of reproductive and conditions in cattle. Prof. Anim. Sci. 18:26-32.

Chavatte-Palmer, P., N. de Sousa, P. Laigre, S. Camous, A. A. Ponter, J. F. Beckers, and Y. Heyman. 2006. Ultrasound fetal measurements and pregnancy associated glycoprotein secretion in early pregnancy in cattle recipients carrying somatic clones. Theriogenology 66:829-840.

Del Vecchio, R. P., W. D. Sutherland, and R. G. Sasser. 1995a. Effect of pregnancy-specific protein $\mathrm{B}$ on luteal cell progesterone, prostaglandin, and oxytocin production during two stages of the bovine estrous cycle. J. Anim. Sci. 73:2662-2668.

Del Vecchio, R. P., W. D. Sutherland, and R. G. Sasser. 1995b. Prostaglandin F2 alpha, progesterone and oxytocin production by cultured bovine luteal cells treated with prostaglandin E2 and pregnancy-specific protein B. Prostaglandins 50:137-150.

Del Vecchio, R. P., W. D. Sutherland, and R. G. Sasser. 1996. Bovine luteal cell production in vitro of prostaglandin E2, oxytocin and progesterone in response to pregnancy-specific protein B and prostaglandin F2 alpha. J. Reprod. Fertil. 107:131-136.

Ferguson, J. D., D. T. Galligan, and N. Thomsen. 1994. Principal descriptors of body condition score in Holstein cows. J. Dairy Sci. 77:2695-2703.

Gabor, G., F. Toth, L. Ozsvari, Z. Abonyi-Toth, and R. G. Sasser. 2007. Early detection of pregnancy and embryonic loss in dairy cattle by ELISA tests. Reprod. Domest. Anim. 42:633-636.

Gajewski, Z., N. Melo de Sousa, J. F. Beckers, B. Pawlinski, M. Olszewska, R. Thun, and M. Kleczkowski. 2008. Concentration of bovine pregnancy associated glycoprotein in plasma and milk: Its application for pregnancy diagnosis in cows. J. Physiol. Pharmacol. 59(Suppl. 9):55-64.

Green, J. A., T. E. Parks, M. P. Avalle, B. P. Telugu, A. L. McLain, A. J. Peterson, W. McMillan, N. Mathialagan, R. R. Hook, S. Xie, and R. M. Roberts. 2005. The establishment of an ELISA for the detection of pregnancy-associated glycoproteins (PAG) in the serum of pregnant cows and heifers. Theriogenology 63:1481-1503.

Green, J. A., S. Xie, X. Quan, B. Bao, X. Gan, N. Mathialagan, J. F. Beckers, and R. M. Roberts. 2000. Pregnancy-associated bovine and ovine glycoproteins exhibit spatially and temporally distinct expression patterns during pregnancy. Biol. Reprod. 62:1624-1631.

Green, J. A., S. Xie, and R. M. Roberts. 1998. Pepsin-related molecules secreted by trophoblast. Rev. Reprod. 3:62-69.

Heyman, Y., P. Chavatte-Palmer, D. LeBourhis, S. Camous, X. Vignon, and J. P. Renard. 2002. Frequency and occurrence of lategestation losses from cattle cloned embryos. Biol. Reprod. 66:6-13.

Humblot, P. 2001. Use of pregnancy specific proteins and progesterone assays to monitor pregnancy and determine the timing, frequencies and sources of embryonic mortality in ruminants. Theriogenology 56:1417-1433.

Humblot, P., S. Camous, J. Martal, J. Charlery, N. Jeanguyot, M. Thibier, and G. Sasser. 1988. Diagnosis of pregnancy by radioimmunoassay of a pregnancy-specific protein in the plasma of dairy cows. Theriogenology 30:257-267.
Inskeep, E. K. 2004. Preovulatory, postovulatory, and postmaternal recognition effects of concentrations of progesterone on embryonic survival in the cow. J. Anim. Sci. 82(E-Suppl):E24-39.

Inskeep, E. K., and R. A. Dailey. 2005. Embryonic death in cattle. Vet. Clin. North Am. Food Anim. Pract. 21:437-461.

Karen, A., A. C. Bajcsy, R. Minoia, R. Kovacs, N. M. De Sousa, J. F. Beckers, J. Tibold, I. Madl, and O. Szenci. 2014. Relationship of progesterone, bovine pregnancy-associated glycoprotein-1 and nitric oxide with late embryonic and early fetal mortalities in dairy cows. J. Reprod. Dev. 60:162-167.

Lopez-Gatius, F., J. M. Garbayo, P. Santolaria, J. Yaniz, A. Ayad, N. M. de Sousa, and J. F. Beckers. 2007a. Milk production correlates negatively with plasma levels of pregnancy-associated glycoprotein (PAG) during the early fetal period in high producing dairy cows with live fetuses. Domest. Anim. Endocrinol. 32:29-42.

Lopez-Gatius, F., R. H. Hunter, J. M. Garbayo, P. Santolaria, J. Yaniz, B. Serrano, A. Ayad, N. M. de Sousa, and J. F. Beckers. 2007b. Plasma concentrations of pregnancy-associated glycoprotein-1 (PAG-1) in high producing dairy cows suffering early fetal loss during the warm season. Theriogenology 67:1324-1330.

Lucy, M. C. 2001. Reproductive loss in high-producing dairy cattle: Where will it end? J. Dairy Sci. 84:1277-1293.

Mann, G. E., and G. E. Lamming. 2001. Relationship between maternal endocrine environment, early embryo development and inhibition of the luteolytic mechanism in cows. Reproduction 121:175180.

Parr, M. H., M. P. Mullen, M. A. Crowe, J. F. Roche, P. Lonergan, A. C. Evans, and M. G. Diskin. 2012. Relationship between pregnancy per artificial insemination and early luteal concentrations of progesterone and establishment of repeatability estimates for these traits in Holstein-Friesian heifers. J. Dairy Sci. 95:2390-2396.

Pohler, K. G., T. W. Geary, C. L. Johnson, J. A. Atkins, E. M. Jinks, D. C. Busch, J. A. Green, M. D. MacNeil, and M. F. Smith. 2013. Circulating bovine pregnancy associated glycoproteins are associated with late embryonic/fetal survival but not ovulatory follicle size in suckled beef cows. J. Anim. Sci. 91:4158-4167.

Pursley, J. R., M. C. Wiltbank, J. S. Stevenson, J. S. Ottobre, H. A. Garverick, and L. L. Anderson. 1997. Pregnancy rates per artificial insemination for cows and heifers inseminated at a synchronized ovulation or synchronized estrus. J. Dairy Sci. 80:295-300.

Ribeiro, E. S., R. G. Bruno, A. M. Farias, J. A. Hernandez-Rivera, G. C. Gomes, R. Surjus, L. F. Becker, A. Birt, T. L. Ott, J. R. Branen, R. G. Sasser, D. H. Keisler, W. W. Thatcher, T. R. Bilby, and J. E. Santos. 2014. Low doses of bovine somatotropin enhance conceptus development and fertility in lactating dairy cows. Biol. Reprod. 90:10.

Ribeiro, E. S., F. S. Lima, L. F. Greco, R. S. Bisinotto, A. P. Monteiro, M. Favoreto, H. Ayres, R. S. Marsola, N. Martinez, W. W. Thatcher, and J. E. Santos. 2013. Prevalence of periparturient diseases and effects on fertility of seasonally calving grazing dairy cows supplemented with concentrates. J. Dairy Sci. 96:5682-5697.

Sangsritavong, S., D. K. Combs, R. Sartori, L. E. Armentano, and M. C. Wiltbank. 2002. High feed intake increases liver blood flow and metabolism of progesterone and estradiol-17beta in dairy cattle. J. Dairy Sci. 85:2831-2842.

Santos, J. E., R. S. Bisinotto, E. S. Ribeiro, F. S. Lima, L. F. Greco, C. R. Staples, and W. W. Thatcher. 2010. Applying nutrition and physiology to improve reproduction in dairy cattle. Soc. Reprod. Fertil. Suppl. 67:387-403.

Santos, J. E., W. W. Thatcher, R. C. Chebel, R. L. Cerri, and K. N. Galvao. 2004. The effect of embryonic death rates in cattle on the efficacy of estrus synchronization programs. Anim. Reprod. Sci. 82-83:513-535.

Sartori, R., R. Sartor-Bergfelt, S. A. Mertens, J. N. Guenther, J. J. Parrish, and M. C. Wiltbank. 2002. Fertilization and early embryonic development in heifers and lactating cows in summer and lactating and dry cows in winter. J. Dairy Sci. 85:2803-2812.

Sasser, R. G., C. A. Ruder, K. A. Ivani, J. E. Butler, and W. C. Hamilton. 1986. Detection of pregnancy by radioimmunoassay of a 
novel pregnancy-specific protein in serum of cows and a profile of serum concentrations during gestation. Biol. Reprod. 35:936-942.

Seals, R. C., J. W. Lemaster, F. M. Hopkins, and F. N. Schrick. 1998. Effects of elevated concentrations of prostaglandin F2 alpha on pregnancy rates in progestogen supplemented cattle. Prostaglandins Other Lipid Mediat. 56:377-389.

Telugu, B. P., A. M. Walker, and J. A. Green. 2009. Characterization of the bovine pregnancy-associated glycoprotein gene family-analysis of gene sequences, regulatory regions within the promoter and expression of selected genes. BMC Genomics 10:185.

Thompson, I. M., R. L. Cerri, I. H. Kim, J. A. Green, J. E. Santos, and W. W. Thatcher. 2010. Effects of resynchronization programs on pregnancy per artificial insemination, progesterone, and pregnancy-associated glycoproteins in plasma of lactating dairy cows. J. Dairy Sci. 93:4006-4018.

Vasconcelos, J. L., O. G. Sa Filho, P. L. Justolin, P. Morelli, F. L. Aragon, M. B. Veras, and S. Soriano. 2011. Effects of postbreeding gonadotropin treatments on conception rates of lactating dairy cows subjected to timed artificial insemination or embryo transfer in a tropical environment. J. Dairy Sci. 94:223-234.

Weems, Y. S., L. Kim, V. Humphreys, V. Tsuda, R. Blankfein, A. Wong, and C. W. Weems. 2007. Effect of luteinizing hormone
(LH), pregnancy-specific protein B (PSPB), or arachidonic acid (AA) on secretion of progesterone and prostaglandins (PG) E (PGE; PGE(1) and PGE(2)) and F(2alpha) (PGF(2alpha)) by ovine corpora lutea of the estrous cycle or pregnancy in vitro. Prostaglandins Other Lipid Mediat. 84:163-173.

Weems, Y. S., M. A. Lammoglia, H. R. Vera-Avila, R. D. Randel, C. King, R. G. Sasser, and C. W. Weems. 1998. Effect of luteinizing hormone (LH), PGE2, 8-EPI-PGE1, 8-EPI-PGE2, trichosanthin, and pregnancy specific protein $\mathrm{B}$ (PSPB) on secretion of progesterone in vitro by corpora lutea (CL) from nonpregnant and pregnant cows. Prostaglandins Other Lipid Mediat. 55:27-42.

Wilson, S. J., R. S. Marion, J. N. Spain, D. E. Spiers, D. H. Keisler, and M. C. Lucy. 1998. Effects of controlled heat stress on ovarian function of dairy cattle. 1. Lactating cows. J. Dairy Sci. 81:21242131.

Wooding, F. B., R. M. Roberts, and J. A. Green. 2005. Light and electron microscope immunocytochemical studies of the distribution of pregnancy associated glycoproteins (PAG) throughout pregnancy in the cow: Possible functional implications. Placenta 26:807-827. 